\title{
A EDUCAÇÃO CIÊNCIA, TECNOLOGIA E SOCIEDADE NO CURSO DE LICENCIATURA EM CIÊNCIAS DA UFPR LITORAL
}

\author{
TAMARA DIAS DOMICIANO ${ }^{*}$ \\ https://orcid.org/0000-0001-5346-4827 \\ LEONIR LORENZETTI ${ }^{\text {** }}$ \\ https://orcid.org/0000-0002-0208-2965
}

RESUMO: A Educação Ciência, Tecnologia e Sociedade (CTS) corresponde a um Ensino de Ciências socialmente comprometido. Contudo, para que essa abordagem ocorra no ambiente escolar, é preciso discutir, na formação de professores, a educação CTS. Devido a particularidades que apontam esse caminho, o curso de Licenciatura em Ciências da UFPR Litoral tornou-se alvo desta pesquisa que objetiva analisar as abordagens da educação CTS presentes no Projeto Pedagógico do Curso de Licenciatura em Ciências da UFPR Litoral, na percepção e na prática dos docentes formadores. A partir de um estudo de caso, com base no Projeto Pedagógico do Curso, observações e entrevistas, foi possível constatar abordagens da educação CTS crítica, com potencialidade de formar professores críticos, que compreendem as relações sociais da ciência e da tecnologia, e conscientes de seu papel social.

Palavras-chave: Educação CTS. Educação em Ciências. Formação inicial.

\section{LA EDUCACIÓN CIENCIA, TECNOLOGÍA Y SOCIEDAD EN LA CARRERA DE LICENCIATURA EN CIENCIAS DE LA UFPR LITORAL}

RESUMEN: La Educación en Ciencia, Tecnología y Sociedad (CTS) corresponde a una Enseñanza en Ciencias comprometida socialmente. Sin embargo, para que este enfoque se produzca en el entorno escolar, es necesario discutir en la formación del profesorado la educación CTS. Debido a las particularidades que indican este camino, la carrera de Licenciatura en Ciencias de la UFPR Litoral se ha convertido en el objetivo de esta investigación, que intenta analizar los enfoques de educación CTS presentes

${ }^{*}$ Mestra e Doutoranda do Programa
de Educação em Ciências e em
Matemática da Universidade Federal
do Paraná. Grupo de Estudos e
Pesquisa em Alfabetização
Científica e Tecnológica.

* Mestra e Doutoranda do Programa de Educação em Ciências e em do Paraná. Grupo de Estudos e Pesquisa em Alfabetização Científica e Tecnológica. E-mail:<leonirlorenzetti22@gmail.com>.

\footnotetext{
' Universidade Federal do Paraná, Programa de Educação em Ciências e em Matemática, Curitiba, PR - Brasil.
} 
en el Proyecto Pedagógico de la Carrera de Licenciatura en Ciencias de la UFPR Litoral, en la percepción y práctica de los docentes que imparten la formación. A partir de un estudio de caso, basado en el Proyecto Pedagógico de la Carrera, observaciones y entrevistas, fue posible verificar los enfoques de educación de CTS crítica, con el potencial de formar a maestros críticos, que comprenden las relaciones sociales de la ciencia y la tecnología y que son conscientes de su rol social. Palabras clave: Educación CTS. Educación en Ciencia. Formación inicial.

THE SCIENCE, TECNOGOLY AND SOCIETY EDUCATION IN SCIENCE TEACHING DEGREE COURSE OF UFPR COST

ABSTRACT: Science, Technology and Society Education (CTS) corresponds to a socially committed Science Education. However, for this approach to occur in the school environment, it is necessary to discuss the CTS education in teacher training. Due to particularities that point this way, the UFPR Litoral Science Degree course has become the target of this research that aims to analyze the approaches of CTS education present in the UFPR Litoral Science Degree Pedagogical Project, in perception and practice of the teaching teachers. From a case study, based on the Pedagogical Project of the Course, observations and interviews, it was possible to verify critical CTS education approaches, with the potential to train critical teachers, understanding the social relations of science and technology and aware of their social role.

Keywords: CTS education. Science education. Initial formation. 


\section{INTRODUÇÃO}

Em suas origens, os debates em torno das interações Ciência, Tecnologia e Sociedade (CTS) foram resultantes de movimentos que emergiram no período pós Segunda Guerra Mundial. Nos Estados Unidos da América, discutia-se sobre as implicações da produção científica e tecnológica sobre as instâncias sociais, ambientais, políticas e econômicas. Já na Europa, os questionamentos eram acerca do positivismo e da neutralidade que acompanhavam a ciência e a tecnologia. Estas constituíram-se nas duas principais tradições de estudos CTS (AULER, 2008)

No contexto da América Latina, o Pensamento Latino Americano em Ciência, Tecnologia e Sociedade, ou PLACTS, termo alcunhado por Dagnino, Thomas e Davyt (1996), se desenvolveu como resposta às necessidades locais. Dentre elas, a condição de região subdesenvolvida e dependente de importação tecnológica, além da insatisfação ao modelo institucional de desenvolvimento linear de ciência e tecnologia, herdado dos países nortenhos.

Tinha-se em mente que a América Latina possuía uma capacidade científica de superar os obstáculos que impediam seu desenvolvimento, mas a baixa demanda social de pesquisa proveniente de governos e empresas, deixava este potencial em segundo plano. Esta barreira estava e ainda está estritamente relacionada às condições históricas, políticas e periféricas da região (DAGNINO, 2015).

Diferentemente do caráter acadêmico da Europa, ou ativista da América do Norte, as discussões que surgiram na América Latina refletiam sobre as funções das políticas públicas em relação à CT, configurando um Pensamento Latino Americano em Política Científica e Tecnológica (PCT) (VACCAREZZA, 1998).

Segundo Vaccarezza (1998), com a emersão do Pensamento Latino Americano em PCT, o atraso científico e tecnológico passou a ser entendido a partir do contexto histórico e cultural da sociedade. Dessa forma, qualquer política pública de superação deveria estar alicerçada nas condições reais destes países, e não no emprego de receitas prescritas de sociedades desenvolvidas.

Um dos pilares fundamentais do Pensamento Latino Americano em PCT é a crítica ao modelo de inovação linear da ciência, que em seu cerne, postulava a dependência das sociedades de terceiro mundo na produção e aplicação do conhecimento científico, resultando em desenvolvimento, mas que nunca foi alcançado (VACCAREZZA, 1998).

O Quadro1 sintetiza as diferenças entre as três tradições dos estudos CTS. 
Quadro 1. Diferença entre tradições de estudos CTS

\begin{tabular}{|c|c|c|}
\hline Tradição europeia & Tradição americana & PLACTS \\
\hline $\begin{array}{l}\text { Institucionalização } \\
\text { acadêmica na Europa } \\
\text { (em suas origens) }\end{array}$ & $\begin{array}{l}\text { Institucionalização } \\
\text { administrativa e acadêmica } \\
\text { nos EUA (em suas origens) }\end{array}$ & $\begin{array}{l}\text { Institucionalização política } \\
\text { e acadêmica na América } \\
\text { Latina (em suas origens) }\end{array}$ \\
\hline $\begin{array}{c}\text { Ênfase nos fatores sociais } \\
\text { antecedentes }\end{array}$ & $\begin{array}{c}\text { Ênfase nas consequências } \\
\text { sociais }\end{array}$ & $\begin{array}{l}\text { Ênfase nas políticas } \\
\text { públicas e economia }\end{array}$ \\
\hline $\begin{array}{l}\text { Atenção à ciência e, } \\
\text { secundariamente, } \\
\text { à tecnologia }\end{array}$ & $\begin{array}{l}\text { Atenção à tecnologia e, } \\
\text { secundariamente, à ciência }\end{array}$ & $\begin{array}{l}\text { Atenção à ciência } \\
\text { e tecnologia }\end{array}$ \\
\hline Caráter teórico e descritivo & Caráter prático e valorativo & Caráter político e social \\
\hline $\begin{array}{l}\text { Marco explicativo: } \\
\text { ciências sociais } \\
\text { (sociologia, psicologia, } \\
\text { antropologia etc.) }\end{array}$ & $\begin{array}{l}\text { Marco avaliativo: ética, } \\
\text { teoria da educação. }\end{array}$ & $\begin{array}{l}\text { Marco reflexivo: Ciências } \\
\text { Sociais (sociologia, } \\
\text { antropologia, economia, } \\
\text { administração) }\end{array}$ \\
\hline
\end{tabular}

Fonte: Os Autores (2019).

Atualmente os estudos CTS são definidos como um campo de trabalho bem consolidado, com caráter interdisciplinar, organizado em torno de críticas às tradicionais imagens de CT.

No campo da Educação, a expressão "Ciência, Tecnologia e Sociedade" emergiu entre no período de 1970 e 1980, a partir de trabalhos publicados nesta época, dentre eles o de Paul Hurd, em 1975, "Science, technology, and society: new goals for interdisciplinary science teaching”, e o de John Ziman de 1980, “Teaching and learning about science and society", onde foram empregados pela primeira vez a sentença "science, technology and society", ou "STS", para designar uma nova forma de se entender a educação científica (RIBEIRO; SANTOS; GENOVESE, 2017).

A efetivação de uma educação nesse direcionamento, requer educadores conscientes de seu papel social de formador dos futuros cidadãos, em uma sociedade cada vez mais permeada por CT. Para tanto, se faz necessário buscar novas possibilidades para a formação de professores, em especial, discutese a formação de professores de ciências, por julgar que estes são diretamente impactados pelas mudanças na sociedade, advindas da produção de conhecimentos científicos e tecnológicos.

Neste sentido, o curso de Licenciatura em Ciências, da Universidade Federal do Paraná (UFPR) Setor Litoral, buscou inovar na formação inicial de professores. Com suas bases em Freire (2016), a partir de uma proposta de ensino interdisciplinar e dialógico, o curso visa proporcionar um espaço de formação inovador para professores de ciências, com o reconhecimento do seu papel social a ser desempenhado (UFPR, 2014). 
Diante disso, o objetivo deste estudo foi analisar as abordagens da educação CTS presentes no Projeto Pedagógico do Curso de Licenciatura em Ciências da UFPR Litoral, na percepção e na prática dos docentes formadores.

Esclarece-se que há uma diversidade de nomenclaturas que se referem aos estudos sobre as interações CTS. Neste sentido, o termo "Movimento CTS" é utilizado quando examinado a perspectiva histórica dos processos de crítica ao tradicional modelo de CT, chamando de "Estudos CTS" ou "ECTS" o campo de pesquisa e trabalho resultante destes movimentos. Além disso, "Educação CTS" refere-se à apropriação das discussões deste campo no âmbito educacional, e "Abordagem CTS" trata das diversas possibilidades de abordar a educação CTS no processo de ensino e aprendizagem.

\section{EDUCAÇÃO CTS E ENSINO DE CIÊNCIAS}

A educação CTS está atrelada à necessidade de centralizar os objetivos do Ensino de Ciências na formação de sujeitos alfabetizados científica e tecnologicamente para tomada de decisões. Nesse contexto, a ciência passa a ser reconhecida como uma construção social, com interesses políticos e econômicos, assim como a tecnologia passa a ser vista não mais como aplicação da ciência, mas como um novo corpo de conhecimentos (AULER; DELIZOICOV, 2001; SANTOS, 2008).

Contudo, ao desenvolver o ensino por meio de abordagens CTS, deve-se ter o cuidado para não cair em aspectos reducionistas do campo de estudos. A perspectiva reducionista, segundo Auler e Delizoicov (2001), está relacionada à reprodução dos mitos ou concepções que consolidam uma percepção distorcida de CT, discutidas nas pesquisas de Gil-Perez et. al. (2001) e Auler (2002). Além disso, deve-se ter a cautela para não priorizar aspectos científicos e tecnológicos, negligenciando as dimensões sociais, políticas, econômicas e culturais, intrinsicamente relacionadas à formação crítica para a cidadania.

Ignorar essas dimensões em uma educação CTS, poderia recair no que Auler (2011) colocou como um retorno à tecnocracia, reforçando o imaginário de que apenas os especialistas em conhecimentos científicos e tecnológicos estariam aptos a tomar decisões. Ao contrário, concorda-se com o autor que "os critérios que pautam a tomada de decisão, muitas vezes, estão circunscritos a esse campo” (AULER, 2011, p. 82).

Entende-se que ao tratar da Educação CTS em uma perspectiva reducionista, algumas concepções ingênuas sobre CT prevalecem, tal como o tratamento da tecnologia como aplicação da ciência. $\mathrm{Na}$ atualidade, quase tudo que circunda a sociedade diz respeito à tecnologia, tornando-a intrínseca aos modos de vida. Frente a este cenário, a tecnologia também passou a ser reduzida a aplicações, sendo associada a instrumentos e aparatos tecnológicos, como celulares, computadores e robôs (SOLBES; VILCHES, 1992; MIRANDA, 2002).

Em uma perspectiva reduzida, também podem surgir tratamentos da ciência como um processo indutivista e de desenvolvimento linear. Há um entendimento que prevalece na academia, de que só pode ser considerado ciência aquilo que passa por todas as etapas do Método Científico. Aliado a isso, os conhecimentos científicos são compreendidos como cumulativos, resultando em uma perspectiva linear da ciência, na qual se entende que quanto maior for o 
desenvolvimento científico, mais resultará em crescimento econômico e bem-estar social (GIL-PÉREZ et al., 2001).

Ainda nesta direção, algumas abordagens na educação CTS de forma reducionista podem reforçar padrões tecnocráticos de decisões. Como defendido por Auler (2011), deve se ter o cuidado com debates que colocam a ciência e a tecnologia como fontes de conhecimentos fundamentais para a sociedade possuir para tomadas de decisões. Desta forma, é reforçada a perspectiva tecnocrática, colocando apenas aqueles que possuem conhecimentos científicos e tecnológicos como qualificados a tomar decisões na sociedade.

Ademais, em uma abordagem reduzida na educação CTS, prevalece o mito de neutralidade da ciência e da tecnologia, pressupondo que a condução da produção científica e tecnológica seja isenta de valores (GIL-PÉREZ et al., 2001; AULER, 2002). Desconsidera-se nessa visão as intencionalidades dos envolvidos nos processos da construção do conhecimento científico e tecnológico, desde os cientistas e tecnólogos, até os responsáveis pelos governos e agências de fomento.

Em contrapartida, a perspectiva ampliada, ou crítica como foi chamada neste estudo, está relacionada à compreensão das interações estabelecidas entre os campos científicos, tecnológicos e sociais (AULER; DELIZOICOV, 2001). Para além disso, considera-se que a perspectiva da educação CTS crítica, vai ao encontro do colocado por Freire (2016, p. 120) que "significa romper com os esquemas verticais característicos da educação bancária”. Por outro lado, a educação problematizadora, possui "caráter autenticamente reflexivo", colocando os estudantes como "seres no mundo e com o mundo" (FREIRE, 2016, p. 104).

Conjuntamente, há uma relação estreita entre a educação CTS crítica no contexto do Brasil com o PLACTS, visto a necessidade de se pensar o Ensino de Ciências a partir da realidade local, superando as condições de dominação, tanto cultural quanto econômica do país.

Neste direcionamento, ao tratar da educação CTS em uma perspectiva crítica, pressupõe-se que os conteúdos da CT serão abordados a partir dos pressupostos da contextualização. Segundo Santos (2008), o Ensino de Ciências tem sido trabalhado de forma descontextualizada nas escolas, resumindo-se à memorização de conceitos e nomenclaturas, impossibilitando o estabelecimento de relações entre CT e a realidade pelos estudantes. Neste formato de ensino fala-se da "realidade como algo parado, estático, compartimentado e bem-comportado" (FREIRE, 2016, p. 103). Há ainda de se colocar, que em muitas situações, a simples exemplificação é considerada contextualização, servindo como pano de fundo para encobrir um currículo puramente enciclopédico (SANTOS, 2008).

Além da contextualização, entende-se como básico em uma proposta de educação CTS crítica, a abordagem interdisciplinar dos conhecimentos. Uma postura disciplinar, centrada apenas em conhecimentos científicos e tecnológicos para olhar o mundo e tomar decisões, reforça as concepções ingênuas de neutralidade e tecnocracia. Coloca-se então, que o professor deve assumir uma atitude interdisciplinar, sendo imprescindível em seu processo formativo buscar conhecimentos de outras áreas (CARVALHO; GIL-PÉREZ, 2011). Caso contrário, a compartimentalização e fragmentação continuará sendo a prática vigente do ensino. 
Neste mesmo caminho, é fundamental tratar de aspectos relacionados à natureza da ciência $(\mathbf{N d C})$ e natureza da tecnologia (NdT), desconstruindo concepções ingênuas tradicionais sobre o desenvolvimento científico e tecnológico. Desde seus primórdios, o Ensino de Ciências pauta-se apenas nos produtos do desenvolvimento científico e tecnológico, imprimindo uma visão de CT como algo a-histórico, verdadeiro e livre de erros (GIL-PÉREZ et al., 2001; CARVALHO; GIL-PÉREZ, 2011). Para haver uma mudança na forma com que a ciência é ensinada, precisa-se superar as concepções ingênuas ou mitos propagados sobre CT. No entanto, alguns problemas como a fragmentação do ensino e a formação deficitária de professores, dificulta mudanças significativas na forma como o Ensino de Ciências é praticado (AULER, 2011).

Ao tratar da educação CTS, deve-se pensar, para além dos conhecimentos a serem abordados, na forma com que será praticado o ensino, superando modelos tradicionais. Segundo Freire (2013, p. 24), um dos saberes indispensáveis ao professor em formação, é convencer-se "definitivamente de que ensinar não é transferir conhecimento, mas criar as possibilidades para a sua produção ou sua construção". Daí surge a necessidade do diálogo, pois somente a partir da dialogicidade os indivíduos se abrem ao mundo e o transformam, ganhando significação como sujeitos históricos.

Sabe-se que a formação ambiental de um ensino transmissivo, como colocado por Carvalho e Gil-Perez (2011), durante o longo período que os docentes permaneceram como estudantes, transformam-se em um obstáculo para práticas dialógicas, sendo fundamental a reflexão crítica dos futuros docentes para superar a dicotomia educador-educando.

Partindo do princípio que os conhecimentos científicos são respostas a perguntas (BACHELARD, 1996), uma proposta de educação CTS, de acordo com Aikenhead (1994), deve partir da problematização de situações concretas, seja local ou global, passando pelo estudo das tecnologias e conceitos científicos envolvidos, para então retornar à sociedade com uma análise crítica.

Uma educação que se diga verdadeiramente libertadora, e também pautada na educação CTS crítica, "não pode ser a do depósito de conteúdo, mas a da problematização dos homens em suas relações com o mundo" (FREIRE, 2016, p. 118). É na problematização das relações dos sujeitos com os outros e com o mundo, que ele se descobre como ser histórico, capaz de atuar e transformar sua realidade (FREIRE, 2016).

Defende-se que o Ensino de Ciências, colabora para uma compreensão mais crítica sobre assuntos que demandam participação pública. Por esse motivo, situações de tomadas de decisões que envolvam aspectos da realidade e que exigem uma análise tanto no que diz respeito à CT quanto a outros âmbitos, como político e cultural, deveriam ser abordados no processo de ensino e aprendizagem (AULER, 2011).

Há também de se considerar que a formação inicial de professores de ciências deveria proporcionar espaços para que aprendam a aprender, estando preparados para buscar novos conhecimentos em função das mudanças no Ensino de Ciências, possibilitando abordagens educacionais CTS em sala de aula (CARVALHO; GIL-PÉREZ, 2011). 
Adiante são apresentadas as particularidades que destacam o curso de Licenciatura em Ciências da UFPR Setor Litoral, e de como ele se diferencia de outros cursos de formação de professores.

\section{2. $O$ CURSO DE LICENCIATURA EM CIÊNCIAS DA UFPR LITORAL}

O curso de Licenciatura em Ciências, iniciado no segundo semestre de 2008, na UFPR Litoral, foi criado com o objetivo de "preencher a lacuna de professores que consigam promover o diálogo entre as diferentes áreas das Ciências Naturais para a Educação Básica” (UFPR, 2014, p. 14). Além disso, havia um interesse governamental para a implementação deste curso na região, por conta do baixo número de professores nesta área para as escolas locais (JOUCOSKI, 2015).

A organização curricular do curso é composta por três fases, divididas ao longo do período dos quatro anos de formação: 1) conhecer e compreender (1 a 2 semestres), nesta etapa o estudante é provocado a reconhecer e fazer uma releitura crítica da realidade em que se insere, por meio de problematizações; 2) compreender e propor (1 a 4 semestres), onde há um aprofundamento científico que irá auxiliar o estudante na construção de um diagnóstico e planejamento de ações para resolução das problemáticas encontradas; 3 ) propor e agir (1 a 2 semestres), onde o estudante é desafiado a intervir na realidade, como forma de transição para o exercício profissional (UFPR, 2014).

Além disso, há os eixos pedagógicos semanais, que estruturam a grade curricular do curso: Interações Culturais e Humanísticas (ICH), Projetos de Aprendizagem (PA) e Fundamentos Teóricos Práticos (FTP).

Os Fundamentos Teóricos e Práticos cumprem as necessidades formativas do professor de ciências, estipulados pelo Projeto Pedagógico do Curso, sendo caracterizados por temáticas amplas e pertinentes, trabalhados por meio de projetos interdisciplinares e pautados na realidade local, cumprindo com sua proposta de superação da fragmentação do ensino (UFPR, 2014).

Em cada semestre, dois ou três docentes são responsáveis pelo desenvolvimento dos Fundamentos Teóricos e Práticos em cada turma. Estes docentes acompanham todas as atividades do semestre como mediadores do processo de ensino e aprendizagem, com base na prática da docência compartilhada. Segundo Silva e Nicolodi (2016), a docência compartilhada é uma prática de trabalho colaborativo, sem posição de líder, havendo intervenções emergentes das interações entre os docentes, a partir de uma relação horizontal e democrática de fala.

As Interações Culturais e Humanísticas (ICH) são espaços fundamentalmente interdisciplinares, que ocorrem nas quartas-feiras de cada semana. Trata-se do "espaço curricular com maior protagonismo dos estudantes" (JOUCOSKI, 2015, p. 89), e também a proposta mais diferenciada da Instituição. Em linhas gerais, as Interações Culturais e Humanísticas são organizadas por discentes com colaboração de docentes ou mediada por ambos, mas sempre havendo um servidor como responsável, para desenvolver determinadas atividades, fruto de interesse individual ou coletivo, por necessidade formativa, ou ainda diagnosticada a partir da realidade local. Trata-se também de um espaço aberto para a participação da comunidade local. 
O Projeto de Aprendizagem (PA) é o espaço onde os estudantes desenvolvem pesquisas sobre assuntos de interesse pessoal e da forma que desejarem, com a mediação de um professor.

Além dos FTP, ICH e PA há a obrigatoriedade de realização de quatro fases do Estágios Supervisionados de Docência, que ocorrem em sintonia com o PPP da UFPR Litoral e PPC do curso. Na primeira fase, o estudante deve aproximar-se do seu futuro campo de atuação, das dimensões organizacionais e administrativas da escola e das diretrizes curriculares, realizando ao final do semestre um plano de pesquisa/ ação que deverá ser executado na etapa seguinte. Na segunda e terceira fase, o estudante passa a realizar o estágio de monitoria, auxiliando o professor supervisor da escola no planejamento e desenvolvimento das aulas, assim como executa seu plano de pesquisa/ação elaborado anteriormente. No estágio Supervisionado IV, o licenciando é estimulado a realizar a prática de regência, assim como entrega de um registro reflexivo sobre seu projeto de pesquisa/ação, articulado com a literatura, desenvolvida durante as vivências de estágio (UFPR, 2014).

A avaliação dos licenciandos se dá de forma processual durante o projeto, e geralmente ao fim do semestre ocorre a autoavaliação coletiva, na qual cada estudante avalia e reflete sobre as atividades desenvolvidas e seu próprio desempenho, atribuindo a si mesmo um conceito, que será discutido e avaliado pelo coletivo de docentes e discentes da turma, resultando no conceito final do estudante (SILVA; BRIZOLLA; SILVA, 2013; UFPR, 2014).

De acordo com Silva, Brizolla e Silva (2013, p. 534), os primeiros semestres do curso são os que apresentam maior dificuldade para os discentes, visto a proposta pedagógica pautada na autonomia:

A primeira série é um momento tensionado pelas expectativas dos estudantes quanto ao PPC do curso, já que a maioria está habituada a uma metodologia em que, de modo geral, não os coloca como sujeitos do processo de ensino-aprendizagem. A tensão está justamente no desconforto que causa a saída de um processo passivo, em que os estudantes recebem sínteses de conhecimentos reproduzidos, para um processo ativo, em que aumenta exponencialmente a necessidade de participação.

Por conta das características destacadas, o Curso contrasta com outros cursos de formação de professores, tais como Licenciaturas em Ciências Biológicas, Química ou Física. Em geral, estes cursos seguem um formato mais disciplinar, priorizando os conteúdos da ciência, organizados em disciplinas específicas em detrimento da formação pedagógica, que se dá em separado e, usualmente, nos últimos períodos do curso. Além disso, o modelo vigente de ensino é tradicional e verticalizado, em sua maioria, colocando o futuro docente em uma posição apassivada de aprendizagem, sendo avaliado a partir de provas, trabalhos, relatórios, seminários, entre outros.

Levando em consideração suas idiossincrasias, que o curso de Licenciatura em Ciências da UFPR Litoral foi escolhido como espaço para a realização desta pesquisa, seguindo os métodos descritos a seguir. 


\section{PERCURSO METODOLÓGICO}

O percurso que foi realizado nesta pesquisa teve como base metodológica a investigação de natureza qualitativa em educação, com base nos referenciais de Lüdke e André (1986) e como técnica pautou-se nos princípios do estudo de caso (LÜDKE; ANDRÉ, 1986; VENTURA, 2007). Destaca-se que esta pesquisa foi aprovada no Comitê de Ética da UFPR, mediante parecer CEP/SD-PB. N ${ }^{\circ}$ 2368873, na data de 07/11/2017.

Esta pesquisa foi dividida em pesquisa documental, sistematizada a partir do Projeto Pedagógico do Curso de Licenciatura em Ciências e observação participante estruturada por meio do acompanhamento das atividades do curso de Licenciatura em Ciências, com auxílio de gravação e transcrição de áudios.

Ao todo foram acompanhadas 13 aulas dos módulos "Concepções de Ciência e Educação", lecionado na turma ingressante no ano de 2018, no $1^{\circ}$ período do curso, e "Vivências de Docência, Relação Ciências e Sociedade e Prática de Ensino" na turma do $6^{\circ}$ período. Por fim, entrevistas semiestruturadas foram realizadas com os quatro professores formadores dos módulos observados. Respeitando a confidencialidade, estes foram denominados de P1, P2, P3 e P4.

Para garantir o anonimato dos professores, seus nomes foram substituídos, sendo denominados de P1, P2, P3 e P4. O professor P1 possui graduação em licenciatura em Física, mestrado em física e doutorado em Educação em Ciências. Já o P2, é graduado em Ciências Biológicas, bacharel e licenciatura, mestre e doutor em Ciências Bioquímicas. A professora P3 tem formação inicial em bacharelado em Direito, especialista em Interdisciplinaridade e Linguagens, mestre, doutora e pós doutora em Educação. O professor P4 é formado pela Faculdade de Ciências, com habilitação em Química, mestre em Ciências dos Solos e doutor em Química.

A análise foi estruturada no referencial da Análise Textual Discursiva (ATD), proposta por Moraes e Galiazzi (2011). Estabelecida em três fases - unitarização, categorização e metatextos - com base neste método o analista, atribui a eles sentidos e significados, construindo compreensões a partir do conjunto de materiais e resultando nas unidades de significado (MORAES; GALIAZZI, 2006, 2011).

Há dois métodos para construir as categorias de análise: o dedutivo e o indutivo. No método indutivo as categorias são estruturadas antes de se ter contato com o "corpus" de análise, a partir das teorias que fundamentam o estudo, sendo denominadas de "a priori". Já na forma dedutiva, as categorias são resultantes das unidades de análise, organizadas com base nas semelhanças e significados encontrados, derivando as categorias emergentes.

Assim, foram organizadas duas categorias e subcategorias a priori, resultantes da fundamentação teórica sobre o campo da Educação CTS e duas categorias emergentes, provenientes das análises dos dados constituídos a partir do Projeto Pedagógico do Curso, observações e entrevistas realizadas no âmbito do curso de Licenciatura em Ciências da UFPR Litoral, descritas no Quadro 2. 
Quadro 2. Categorias e subcategorias de análise

\begin{tabular}{|c|c|c|}
\hline Categoria & Subcategoria & Descrição \\
\hline \multirow{8}{*}{$\begin{array}{l}\text { Educação CTS } \\
\text { Crítica } \\
\text { Relacionada à } \\
\text { compreensão } \\
\text { das interações } \\
\text { entre os campos } \\
\text { científicos, } \\
\text { tecnológicos } \\
\text { e sociais de } \\
\text { forma crítica } \\
\text { interdisciplinar e } \\
\text { contextualizada. }\end{array}$} & Contextualização & $\begin{array}{l}\text { Conteúdos colocados como } \\
\text { socialmente relevantes; estudo a partir } \\
\text { de situações concretas }\end{array}$ \\
\hline & Interdisciplinaridade & $\begin{array}{l}\text { Interação entre conteúdos e } \\
\text { metodologias de diferentes áreas do } \\
\text { conhecimento; professor com atitude } \\
\text { interdisciplinar }\end{array}$ \\
\hline & $\begin{array}{l}\text { Natureza da Ciência } \\
\text { e Natureza da } \\
\text { Tecnologia }\end{array}$ & $\begin{array}{l}\text { CT como atividade humana, portadora } \\
\text { de valores/interesses, sócio e } \\
\text { culturalmente influenciada; T como } \\
\text { campo de conhecimento; Estudo de T; } \\
\text { Superação das concepções ingênuas }\end{array}$ \\
\hline & Dialogicidade & $\begin{array}{l}\text { Troca de conhecimentos; espaço } \\
\text { democrático de fala; construção } \\
\text { coletiva dos processos de ensino e } \\
\text { aprendizagem; avaliação coletiva e } \\
\text { dialógica }\end{array}$ \\
\hline & Problematização & $\begin{array}{l}\text { Debates de temas sociais reais, } \\
\text { globais ou locais, desenvolvimento de } \\
\text { postura crítica e de reflexão para a } \\
\text { resolução dos problemas utilizando os } \\
\text { conhecimentos necessários }\end{array}$ \\
\hline & Tomada de decisão & $\begin{array}{l}\text { Situações que promovam tomada de } \\
\text { decisão; Situações de escolhas que } \\
\text { promovam o desenvolvimento da } \\
\text { autonomia/responsabilidade }\end{array}$ \\
\hline & $\begin{array}{l}\text { lemergentel } \\
\text { Humanização }\end{array}$ & $\begin{array}{l}\text { Ensino e aprendizagem com foco } \\
\text { na formação integral do sujeito, do } \\
\text { profissional a afetiva, cultural e social }\end{array}$ \\
\hline & $\begin{array}{l}\text { (emergente) Cultura } \\
\text { de participação }\end{array}$ & $\begin{array}{l}\text { Debates que impliquem em } \\
\text { posicionamentos levando em } \\
\text { consideração o coletivo e o interesse } \\
\text { social, bem como a promoção de um } \\
\text { senso de coletividade }\end{array}$ \\
\hline
\end{tabular}




\begin{tabular}{|c|c|c|}
\hline Categoria & Subcategoria & Descrição \\
\hline \multirow{4}{*}{$\begin{array}{l}\text { Enfoque CTS } \\
\text { reduzido } \\
\text { Debates em } \\
\text { torno dos } \\
\text { conhecimentos } \\
\text { científicos e } \\
\text { tecnológicos, } \\
\text { com pouco } \\
\text { diálogo com os } \\
\text { demais âmbitos } \\
\text { da realidade; } \\
\text { concepções } \\
\text { ingênuas de CT. }\end{array}$} & $\begin{array}{l}\text { Ciência Indutivista e } \\
\text { Linear }\end{array}$ & $\begin{array}{l}\text { Ciência concebida única e } \\
\text { exclusivamente por meio do Método } \\
\text { Científico }\end{array}$ \\
\hline & Neutralidade de CT & $\begin{array}{l}\text { Ciência e tecnologia desvinculada de } \\
\text { valores e intencionalidades }\end{array}$ \\
\hline & $\begin{array}{l}\text { Tecnologia como } \\
\text { aplicação }\end{array}$ & $\begin{array}{l}\text { Tecnologia reduzida a aplicações } \\
\text { práticas da ciência }\end{array}$ \\
\hline & Tecnocracia & $\begin{array}{l}\text { Processos de tomada de decisão } \\
\text { centradas em especialistas }\end{array}$ \\
\hline
\end{tabular}

Fonte: Os autores (2019).

Durante o procedimento de análises foi utilizado o software QDA Miner Lite, uma ferramenta gratuita de análise qualitativa de dados, que auxiliou o processo de desconstrução do corpus, unitarização e categorização, etapas da Análise Textual Discursiva.

\section{ENFOQUE CTS NO CURSO DE LICENCIATURA EM CIÊNCIAS DA UFPR LITORAL}

Com o intuito de facilitar a análise, as discussões foram dividas de acordo com as categorias de análise, discutindo-se inicialmente a educação CTS reduzida, seguida da educação CTS crítica.

\subsection{EDUCAÇÃO CTS REDUZIDA}

Uma das categorias de análise definidas a priori foi a educação CTS em uma perspectiva reduzida. Nesta abordagem, por mais que sejam discutidos aspectos sobre as relações entre Ciência, Tecnologia e Sociedade, algumas questões não são levadas em consideração ou, ainda, com forte ênfase nos conhecimentos específicos (SANTOS; AULER, 2011). A Tabela 1 apresenta o número de ocorrências identificadas como educação CTS reduzida no curso. 
A Educação Ciência, Tecnologia e Sociedade no Curso de Licenciatura em Ciências da UFPR 1 itoral

Tabela 1. Número de ocorrências de abordagens de enfoque CTS reduzido

\begin{tabular}{c|c|c|c|c}
\hline Enfoque CTS Reduzido & PPC & Observação & Entrevistas & Total \\
\hline Tecnologia como aplicação da ciência & - & 3 & 6 & 9 \\
\hline Neutralidade da ciência e tecnologia & - & 4 & 1 & 5 \\
\hline Ciência indutivista e linear & - & 8 & 1 & 9 \\
\hline Tecnocracia & - & 4 & - & 4 \\
\hline
\end{tabular}

Fonte: Os autores (2019)

A seguir são apresentadas e caracterizadas com mais detalhes essas ocorrências.

Observando as percepções acerca da tecnologia expressas no curso, nas práticas em sala de aula e nas falas durante a entrevista dos professores formadores foi identificada uma visão reducionista ou ingênua sobre tecnologia assumindo a Tecnologia como aplicação da Ciência, ilustrada nos enxertos das falas dos professores formadores.

A aplicação da ciência que vai resultar em uma tecnologia que a gente pode utilizar, é isso talvez? Pode ser isso? Então a tecnologia assim a grosso modo, mas não estou dizendo que é isso, pode ser uma ciência mais aplicada, pode ser. Talvez né? A grosso modo em não vamos tirar muitas conclusões ainda né. Eu vou colocar aqui ciência aplicada, mas eu vou colocar tudo isso entre aspas porque talvez o texto ainda não tenha explicado tão bem o que que ele quer dizer com essa tecnologia (P1, Aula 8).

[...] a ciência é a produção de conhecimento, a tecnologia é a aplicação dos conhecimentos na forma de instrumentos e técnicas para a sociedade (P2, Entrevista).

Nestas falas dos professores formadores, a tecnologia é colocada como resultante dos conhecimentos científicos, materializando-se em instrumentos. Isto pode ser decorrente da pouca atenção dada à tecnologia na educação em ciências e, até mesmo, em abordagens CTS, na qual o T da sigla é usualmente deixado em segundo plano (GEREMIAS; CASSIANI, 2016). Seguindo ainda esta problemática, a tecnologia também é associada a técnicas, com um fim utilitário.

[...] dá para entender que a ciência é um conhecimento que a gente produz, a técnica é o uso que a gente faz, isso né? (P4, Entrevista).

E aí a tecnologia eu acho que ela está... Ela serve como esses instrumentos. E a sociedade, porque ela está aí, e a gente precisa como papel da Universidade estar nela (P1, Entrevista).

Assim como discutido por Miranda (2002), atualmente tudo que nos cerca está de alguma forma associado a tecnologia, tornando-a inseparável da vida na sociedade. 
Por conta disto, a visão de tecnologia como técnica "é insuficiente para entender a complexidade deste fenômeno social na atualidade" (MIRANDA, 2002, p. 12).

A neutralidade da ciência e tecnologia corresponderam a colocações dos discentes durante as aulas, mas problematizadas logo em seguida pelos professores formadores.

Discente: Em si ela é neutra, mas é aí...

P2: Como que ela é neutra? Aonde que está a neutralidade dela?

Discente: Em princípio, quando lá por exemplo o satélite foi desenvolvido para alcançar mais lugares, mas no final foi privatizado para ser vendido (Aula 6).

P2: Que a tecnologia não é boa nem ruim?

Discente: Não é boa nem ruim, tudo depende do uso que damos a ela (Aula 6).

Nesses diálogos o professor formador buscava fomentar uma discussão entre a turma, iniciada a partir do questionamento "vocês acham que a ciência é neutra ou não é? Qual que é a opinião de vocês?" (P2, Aula 6). No decorrer da aula, alguns discentes se pronunciaram, acreditando que a ciência, no momento de sua produção é neutra e o que irá direcionar se é "boa ou ruim" será resultante dos usos atribuídos a ela.

Ao longo da discussão o professor formador foi desconstruindo essa percepção, apresentando aos discentes todos os processos que estão envolvidos na construção do conhecimento científico e tecnológico, bem como suas implicações nos diversos âmbitos da sociedade.

Em continuidade às subcategorias concernentes a educação CTS reduzida, foram analisadas ao longo do curso possíveis interpretações da ciência como empírica e indutivista, bem como a perspectiva linear.

Os conteúdos que a física, a biologia e a química e as ciências naturais, vamos pensar, dentro da área de ciências, entendem como conteúdos que são é... verdadeiros, para serem passados (P2, Aula 4).

Divulgação dos impactos, relacionados com as possíveis implicações das novas descobertas, então, aí quando eu escutei isso me veio claramente os transgênicos, né? (P1, Aula 8).

Nestas falas são expressas ideias relacionadas principalmente ao Método Científico (GIL-PÉREZ et al., 2001), que confere um caráter de rigidez e confiabilidade, sendo exato e infalível, conduzida por especialistas para a descoberta de novos conhecimentos. Desta forma, são atribuídos aos conteúdos o caráter de "verdades absolutas", desconsiderando os processos envolvidos na produção científica de "idas e vindas", sendo produto de interpretações de sujeitos, contextos sociais e históricos.

Como resultante destas visões, chega-se a percepção da ciência como universal:

Ele vai passar por um processo, que primeiro, ele vai ser produzido como um 
conhecimento, vamos dizer assim, universal, que todo mundo, dentro da ciência, vai concordar que aquilo está certo (P1, Aula 4).

A perspectiva de universalidade do conhecimento endossa modelos como de transferência de políticas e de tecnologias, criticadas pelo PLACTS, além de desvalorizar a produção de conhecimentos de diferentes culturas (DAGNINO; THOMAS; DAVYT, 1996).

Por toda a extensão da investigação houve poucos debates que corresponderam a uma perspectiva tecnocrática em relação à ciência e à tecnologia, estando mais relacionado a um entendimento equivocado sobre o termo tecnocracia.

O que que é decisões tecnocráticas? [...] São decisões que são pautadas por questões técnicas, né? Então nós vamos fazer essa decisão a partir de critérios puramente técnicos (P2, Aula 6).

Discente: Aquele leva em condição o voto de determinadas pessoas?

P2: Não o voto, mas pelo dado científico. Então o dado científico que define o que que vai ser o critério (Aula 6).

O professor formador ao definir o que seria tecnocracia se equivocou ao dizer tratar-se de decisões que são tomadas em consideração a questões técnicas e científicas. Na realidade, a perspectiva tecnocrática diz respeito ao processo de decisões ser conduzido por especialistas, considerados os mais aptos a decidir o que deve ou não ser pesquisado visto seu aporte de conhecimentos da área (AULER, 2002).

\subsection{EDUCAÇÃO CTS CRÍTICA}

A educação CTS crítica pressupõe uma abordagem aprofundada dos estudos sociais da ciência e da tecnologia, tendo em sua gênese a interdisciplinaridade e a contextualização na realidade, seja social, ambiental, cultural ou temporal. Também se faz presente debates sobre natureza da ciência $(\mathrm{NdC})$ e natureza da tecnologia $(\mathrm{Nd} T)$, fortalecendo concepções mais adequadas sobre a construção, usos e demais aspectos envolvidos do conhecimento.

Tendo esses balizadores como ponto de partida, a Tabela 2 apresenta as ocorrências de cada subcategoria que correspondem a abordagens de educação CTS crítica, que se fizeram presentes no curso de Licenciatura em Ciências da UFPR Litoral, levando-se em consideração a análise do PPC do Curso, as observações e entrevistas realizadas. 
Tabela 2. Número de ocorrências de abordagens de enfoque CTS crítico

\begin{tabular}{c|c|c|c|c}
\hline Enfoque CTS Crítico & PPC & Observação & Entrevistas & Total \\
\hline Contextualização & 74 & 98 & 21 & 193 \\
\hline Problematização & 19 & 58 & 12 & 89 \\
\hline Interdisciplinaridade & 63 & 21 & 7 & 91 \\
\hline Dialogicidade & 52 & 95 & 34 & 181 \\
\hline NdC e NdT & 41 & 135 & 24 & 200 \\
\hline Tomada de decisão & 28 & 34 & 10 & 72 \\
\hline Humanização & 16 & 10 & 3 & 29 \\
\hline Cultura de participação & 25 & 39 & 10 & 74 \\
\hline
\end{tabular}

Fonte: Os autores (2019)

A seguir são apresentas as análises e discussões de cada subcategoria elencada, correspondentes à educação CTS crítica.

O curso de Licenciatura em Ciências apresentou grande destaque para a contextualização dos conhecimentos científicos com 193 ocorrências. Dentre essas questões, é recorrente a preocupação com a aproximação destes conhecimentos com a realidade local.

A construção e atualização permanente da organização curricular pressupõem a universidade como lócus de construção e disseminação de conhecimento, o discente como sujeito partícipe da aprendizagem, o docente como mediador do processo e a preocupação com o contexto social coloca a prioridade de atividades formativas incluindo a pesquisa nas áreas de interesse regional (UFPR, 2014, p. 6).

Neste caminho, o PPC do curso se aproxima do colocado por Santos (2008a), o tratamento dos conhecimentos é em seu meio autêntico, conferindo-lhe significado social ao expor sua "preocupação com o contexto social" (UFPR, 2014, p. 6).

Ao longo de todo o texto do Projeto Pedagógico do Curso, a expressão "perceber criticamente a realidade" (UFPR, 2014, p. 7) está presente, veiculada à região do litoral do Paraná. Almeja-se que os futuros professores de ciências, munidos de conhecimentos científicos, juntamente com a análise de aspectos políticos, socioeconômicos, culturais e sociais, passem a compreender sua realidade e do local de sua prática e não somente a conviver com ela.

Ainda dentro desta categoria, além de a formação dos discentes do curso contemplar a contextualização, eles são estimulados a pensar suas práticas enquanto docentes nesta direção. Também há uma aproximação entre contextualização e o rompimento com o processo de ensino transmissivo, criticado por Freire (2016), presente no discurso do professor formador, ao explanar que: 
Então principal era assim, falar existe uma maneira de trabalhar o ensino de ciências que não é o ensino da passagem deconteúdos, relacionar o ensino de ciências com a realidade onde eles estão inseridos (P2, Entrevista).

Este posicionamento concorda com Santos e Mortimer (2002), ao indicar que educação CTS ambiciona um Ensino de Ciências comprometido socialmente, sendo discutido a partir de sua necessidade.

Em relação à Interdisciplinaridade, as análises dos dados constituídos ao longo da pesquisa apontaram que o entendimento que prevalece sobre ciência, no curso de Licenciatura em Ciências, é de um campo do conhecimento interdisciplinar por essência, como exposto na fala do professor formador:

Então a ciência é interdisciplinar. Então é muito difícil você chegar para um biólogo, que está pesquisando biologia, e ele só vai saber a Biologia ele vai saber um pouquinho da química daquilo envolvido, vai saber um pouquinho as vezes da estatística que ele precisa para fazer a contagem, e vai saber um pouquinho daqueles processos da biologia. Então por si só a ciência ela interdisciplinar, ela nasce em interdisciplinar (P1, Aula 8).

Nesta fala, além do professor formador expor a ciência como interdisciplinar, ele rompe com a ideia ilusória de ciência analítica, discutida por Gil-Perez et. al. (2001). Desta forma, os futuros professores passam a perceber que a compartimentalização da ciência apenas dificulta o processo de aprendizagem.

Ademais, para garantir o trabalho interdisciplinar em sala de aula, cada módulo é conduzido por mais de um professor formador de áreas de formação distintas, pautados na prática da docência compartilhada. Na turma do $6^{\circ}$ período, o módulo de Vivências de docência, relação ciências e sociedade e prática de ensino foi mediado por uma professora formada em direito com especializações na área de educação e um professor da área de química, com ênfase em química dos solos. Já o módulo de "concepções de ciência e educação" foi conduzido por um professor formado em biologia, com especialização em bioquímica, enquanto o outro era físico com Pós-Graduação em sociologia da educação.

As atividades do curso de Licenciatura em Ciências são construídas e direcionadas com base na problematização.

Um projeto deve apresentar complexidade e resolução de problemas: o objetivo central do projeto constitui um problema ou uma fonte geradora de problemas, geralmente levantada pelos próprios estudantes, que exige uma atividade para sua resolução (UFPR, 2014, p. 27).

Partindo desta premissa, se torna inconcebível um projeto que não parta de um problema ou um tema. O módulo de Concepções de Ciência e Educação teve como tema central a dengue, sendo que cada coletivo de trabalho elaborou propostas de pesquisa, com base em dúvidas geradas a partir da temática. Para o professor formador: 
Eu acho que um dos pontos que a gente tinha como objetivo, e eu acho que a gente cumpriu. Eu acho que isso está mais claro para nós do que para eles, é que você tem a ciência no dia a dia, e que você pode utilizar essa ciência que está presente no dia a dia, para problematizar em sala de aula (P2, Entrevista).

O professor formador $\mathrm{P} 2$ considerou que um dos maiores aproveitamentos do semestre, para além de vivenciar o processo de ensino a partir da problematização, foi aprender a problematizar e perceber que esta pode ser uma forma de conduzir a prática pedagógica.

Outra subcategoria de análise utilizada, e que se entende como pressuposto de uma educação CTS crítica, é a tomada de decisão. Ressalta-se que a tomada de decisão foi analisada a partir de posicionamentos individuais, que requerem uma criticidade para decidir por si próprio, seja em relação ao processo de aprendizagem ou em situações cotidianas.

Dessa forma, um dos principais focos do curso de Licenciatura em Ciências, centra-se na autonomia dos discentes:

A autonomia dos estudantes é essencial: os alunos são os principais responsáveis pelo desenvolvimento das atividades e pelas escolhas ao longo do projeto (UFPR, 2014, p. 27).

De acordo com essa concepção de ensino, os futuros professores de ciências aprendem cotidianamente que são os principais responsáveis pela construção de seus conhecimentos, sendo colocados diante de situações que requerem posicionamentos e escolhas ao longo de todo percurso.

$\grave{A}$ vista disso, os professores formadores a todo momento buscam debater situações que fomentam a tomada de decisão pelos discentes.

E aî? Eu estava esperando você chegar lá. Como que está por exemplo a discussão acerca do porto de Pontal? Como é que vocês avaliam? (P2, Aula 4).

Nesta discussão, o professor formador estava fazendo alusão à construção de um novo terminal portuário no município de Pontal do Paraná, que tem gerado grandes controvérsias na região, instigando os discentes a se posicionarem avaliando a situação como um todo. Ou seja, todo o cenário é avaliado, não só do ponto de vista dos impactos ambientais, mas sociais e econômicos, antes de tomar uma decisão.

Quanto à Natureza da Ciência e a Natureza da Tecnologia foi constatado durante as análises uma preocupação do curso e docentes em romper com algumas concepções ingênuas e mitos relacionados à ciência e tecnologia (GIL-PÉREZ et al., 2001; AULER, 2002). Por exemplo, uma das questões que está fortemente presente é a apresentação da ciência como construção humana.

A Ciência deve ser apresentada ao indivíduo através de seu caráter de construção coletiva da humanidade, e, portanto, de domínio público (UFPR, 2014, p. 21). 
Com este viés de abordagem, é rompida a ideia de ciência individualista, problematizada por Gil-Perez et. al. (2007), entendendo-a como social e coletiva. Passa-se a considerar todos os sujeitos que estão envolvidos na construção dos conhecimentos científicos e tecnológicos e não como obra de gênios isolados. Também se desmistifica a ilusão da ciência ser de domínio reservado a uma pequena parcela da população, que detém o poder e o saber, sendo apontada como pertencente a toda sociedade.

A perspectiva salvacionista e a neutralidade da ciência também são denunciadas desde o primeiro momento do curso.

[...] além da acessibilidade percorre-se a discussão nas atividades formativas quanto a pluralidade de concepções como expressão do caráter de não neutralidade do conhecimento científico (UFPR, 2014, p. 13).

Na verdade, aqui já é um outro item. A questão é assim a ciência e a tecnologia não vão salvar o mundo (P2, Aula 6).

Assim como discutidos em diversas pesquisas (GIL-PÉREZ et al., 2001, 2001; AULER, 2002), busca-se desconstruir a ideia ilusória da existência de pesquisadores isentos de intencionalidades. A ciência é entendida como portadora de valores sejam eles sociais, políticos ou econômicos, tanto em relação a sua formulação quanto aos seus usos.

A compreensão acerca da dialogicidade foi considerada como um elemento balizador para a formação de professores de ciências, em uma prática condizente com a educação CTS crítica. Na perspectiva dialógica, as ideias de transmissão de conhecimento, verticalidade e passividade do discente, dão lugar a troca de saberes, horizontalidade e protagonismo no espaço educacional (FREIRE, 2013).

As análises indicaram que o diálogo é um dos pilares do curso de Licenciatura em Ciências.

Vivência de relações humanas simétricas e dialógicas; Estudo de cultura e sociedade; Experimentação da construção coletiva e autogestão; Contextualização crítica numa perspectiva libertária; Articulação dos saberes e desejos; Avaliação qualitativa e coletiva (UFPR, 2014, p. 86).

Foi percebido que há um entendimento de horizontalidade e de espaço democrático de fala. Também foi evidenciada a valorização da construção dos encaminhamentos em coletivos, respeitando os espaços de fala e posicionamentos de todos os atores envolvidos. Identificou-se que a intencionalidade de trabalhar em espaços dialógicos está associada a formação de professores que compreendam sua importância e incorporem em sua prática a dialogicidade.

Então a ideia que a gente pudesse oportunizar espaços colaborativos e coletivos né? E que nesses espaços o coletivo fosse tal forma constituinte do processo em si no estágio que ele não se visse e fazendo estágio que não fosse através de um ato 
coletivo para que depois na sua formação ele também pudesse ir para escola mais né pensando em qual é o coletivo queria se constituir (P4, Entrevista).

[...] é fundamental que professores e alunos saibam que a postura dele é dialógica, aberta, curiosa indagadora e não apassivada, enquanto fala ou enquanto ouve (P4, Aula 9).

Com base nisso, há a intenção de que os futuros professores compreendam a necessidade de superar a contradição entre educador e educando, em sua ação docente, existente em uma concepção bancária.

As análises revelaram a ênfase dada para a formação integral do sujeito para além da profissional, convergindo em uma subcategoria emergente referente à humanização.

Muitas são as discussões que colocam em pauta o desenvolvimento humano, a culturalidade, afetividade e valores individuais no curso.

A intenção do processo educativo é o desenvolvimento integral, não apenas no aspecto cognitivo, mas também nos aspectos afetivos, cognitivos e sociais, em uma perspectiva emancipatória e de protagonismo de seus sujeitos e de suas coletividades. Fomentar, construir e disseminar o conhecimento, contribuindo para a formação do cidadão e desenvolvimento humano sustentável (UFPR, 2014, p. 4).

Indo ao encontro do discutido por Freire (2016, p. 110), de que "a ação dos professores identificando-se desde logo, com a dos educandos, deve orientar-se no sentido da humanização de ambos", pode-se afirmar que o curso de Licenciatura em Ciências, objeto desta pesquisa, é verdadeiramente comprometido com uma educação libertadora. Nesta pedagogia humanizadora, estabelecida a partir de uma prática dialógica, a finalidade é a transformação permanente da realidade.

A outra direção que o curso de Licenciatura em Ciências apresentou, tornando-se uma subcategoria emergente, preocupa-se com os processos coletivos que demandam um posicionamento que possuam como ponto de partida o bem comum a todos, denominada de cultura de participação. Há também uma atenção para o fomento da participação pública, engajando os discentes a se manifestaram em espaços decisórios e compreenderem todos os âmbitos de uma sociedade democrática. Estas discussões possuem alta relevância, diante da existência de uma cultura do silêncio, que nasce da relação assimétrica de poder político e econômico, além das relações de dependência entre as nações (DAGNINO; THOMAS; DAVY'T, 1996).

Seguindo este caminho, foi apontada a emergência em conferir significados à participação em processos decisórios para os sujeitos.

Esse é um processo que aí entra dentro daquilo que a gente estava colocando, que é você não conseguir fazer o engajamento público das pessoas, da gente não conseguir fazer com que as pessoas participam dos processos, porque para elas participarem elas têm que ter interesse no processo de participação, tem que entender que aquilo de alguma maneira é interessante que motiva para que façam e desenvolvam essa ação, senão não vai ter essa participação (P2, Aula 4). 
Esta consideração remete à cultura do silêncio (FREIRE, 2016). A sociedade, muitas vezes não percebe como pode alterar o curso das políticas públicas, eximindo-se de participar de decisões. Há uma crença, imposta nas sociedades oprimidas, que de nada adianta participar de espaços democráticos, de se manifestar, pois não mudará a realidade. Por isso, cabe a uma educação e a professores verdadeiramente comprometidos com a vocação ontológica do ser humano de "ser mais", superando esse mito e, em conjunto, lançarem-se na luta pelos seus direitos (FREIRE, 2016).

Em síntese, ficou evidente a prevalência de abordagens da educação CTS em uma perspectiva crítica no contexto do curso de Licenciatura em Ciências em análise. Tanto no Projeto Pedagógico do Curso, quanto na prática em sala de aula e ainda expresso nos posicionamentos dos professores formadores. Há uma clara preocupação com a formação de professores que compreendam seu papel social e com ênfase no desenvolvimento territorial sustentável. Para tanto, tudo o que é abordado ao longo do curso, seja em relação à construção dos projetos, às Interações Culturais e Humanísticas, aos debates e aos fundamentos são relativos à busca incessante em formar sujeitos críticos, para atuação na sua realidade local, que possa resultar em uma cultura de participação.

Assume-se que uma proposta de formação inicial de professores de ciências que leve em consideração as categorias elencadas como precursoras da educação CTS crítica, deveria ter como ponto de partida a realidade local do educando, em qualquer nível de ensino, problematizando situações concretas. Desta forma, os conhecimentos científicos e tecnológicos são debatidos à medida de sua necessidade, para compreender a realidade problematizada, desmitificando concepções ingênuas de CT e tendo sua gênese na contextualização. A interdisciplinaridade é intrínseca nestas situações, sabendo que os problemas da realidade não vêm divididos por disciplinas, exigindo do docente formador uma postura interdisciplinar e dialógica. O trabalho coletivo, primordial para concretizar esta proposta, tanto entre discentes quanto na relação professor-aluno, estabelece uma relação humana, democrática e horizontalizada. Neste formato de conceber o ensino, o posicionamento individual é inerente e possibilita a construção de uma cultura de participação para a ação na realidade.

Por fim, enfatiza-se a necessidade de abordagens CTS serem desenvolvidas tendo como base a educação CTS em uma perspectiva crítica, levando em consideração aspectos da contextualização, interdisciplinaridade, problematização, dialogicidade, tomada de decisão, natureza da ciência, natureza da tecnologia, humanização e cultura de participação. Falar em uma educação e prática docente nesse direcionamento pode parecer utópico para muitos. Porém, entende-se, da mesma forma que colocado por Freire (1979, p. 16), que "o utópico não é o irrealizável; a utopia não é o idealismo", é um processo de "denunciar as ações desumanizantes, anunciando as humanistas" e "por esta razão a utopia é também um compromisso histórico”. A utopia é própria daqueles que buscam a libertação, exigindo um conhecimento crítico da realidade, nas palavras de Freire (1979, p. 16) "a conscientização está evidentemente ligada à utopia, implica em utopia”. 


\section{CONSIDERACִ̃̃ES FINAIS}

As análises empreendidas foram pautadas em duas grandes categorias e subcategorias associadas, desenvolvidas ao longo da pesquisa. A categoria de enfoque CTS reduzido possuía como subcategorias: a) tecnologia como aplicação da ciência; b) ciência indutivista e linear; c) perspectiva tecnocrática e; d) neutralidade de ciência e tecnologia. Já a categoria de enfoque CTS crítico estava correlacionada as subcategorias: a) contextualização; b) interdisciplinaridade, c) natureza da ciência e natureza da tecnologia; d) dialogicidade; e) problematização; f) tomada de decisão; além de duas categorias emergentes de g) humanização e h) cultura de participação.

Os resultados apontaram poucas abordagens do enfoque CTS reduzido, estando a maior problemática na apresentação da tecnologia como aplicação da ciência ou como técnica. Supõe-se que estas discussões se fizeram presentes em razão tanto da formação dos professores formadores não contemplar aspectos sobre a tecnologia, bem como a pouca ênfase dada historicamente aos debates que permeiam os conhecimentos tecnológicos no Ensino de Ciências.

Neste mesmo caminho, discentes recém ingressantes no curso de Licenciatura em Ciências, expressaram uma concepção ingênua de neutralidade da ciência. O mesmo ocorreu com a perspectiva tecnocrática, sendo atribuído pelos discentes a especialistas a tomada de decisão em assuntos relacionados à ciência e tecnologia. Porém, estas visões foram prontamente problematizadas pelos professores formadores, o que assegurou superar este entendimento logo no primeiro semestre do curso.

Por outro lado, o enfoque CTS crítico foi fortemente evidenciado. As categoriais a priori de contextualização, natureza da ciência e natureza da tecnologia e dialogicidade foram as mais presentes, com quase $62 \%$ das ocorrências. Com isso, é incontestável a relevância conferida ao entendimento da ciência como uma construção social, envolta de processos e valores, tratada em seu contexto autêntico. Neste mesmo caminho, é possível afirmar que no curso prevalece uma concepção de educação problematizadora, que tem o diálogo, a horizontalidade e a humanização como ponto de partida para os processos de ensino e aprendizagem.

Ainda em relação às categorias a priori, a interdisciplinaridade e problematização são pressupostos básicos na estrutura do curso, que tem seus princípios no trabalho por projetos. Esta afirmação se materializa na estrutura curricular do curso que permite a flexibilidade, tanto no que diz respeito à disposição dos professores formadores de distintas áreas nos módulos quanto o desenvolvimento das atividades por dois ou mais professores de áreas distintas.

Ao longo da análise também foram identificadas abordagens que envolviam tomada de decisão e a cultura de participação. A tomada de decisão se fez presente em situações que demandavam posicionamentos individuais frente a problemas e a autonomia na condução dos projetos. Já a cultura de participação esteve associada à debates acerca de posicionamentos coletivos e políticas públicas, pautadas no interesse social e nos princípios da democracia.

Destaca-se que o curso não possui respaldo direto nos fundamentos teóricos da educação CTS, não constando em sua estrutura curricular explicitamente menção a este campo de estudos. Contudo, foram identificados elementos tanto em seu Projeto Pedagógico de Curso quanto materializados nas práticas e falas dos 
professores formadores, que vão ao encontro dos pressupostos da educação CTS.

Desta maneira, considera-se que a Licenciatura em Ciências da UFPR Setor Litoral apresenta um caminho para repensar a formação inicial de professores. Além de profissionais com concepções mais apropriadas de ciência, sua estrutura curricular é pautada em uma educação que busca a libertação dos oprimidos, entendendo-a como uma ferramenta para leitura crítica de mundo.

Há uma premência de pesquisas que discutam alternativas para a formação inicial de professores, com foco não somente no conteúdo específico ou sua didática em sala de aula, mas com olhar atento para as dimensões sociais e políticas que implicam a ação destes como docentes e sujeitos em uma sociedade democrática. Além disso, são necessários estudos que investiguem como esta proposta impacta o profissional formado, verificando se sua prática condiz com a formação oferecida pelo curso.

Por fim, esta pesquisa indica contribuições que a Educação CTS em uma perspectiva crítica oferece para a formação inicial de professores. Ao longo do processo de formação, é possibilitado aos licenciandos um espaço de superação de concepções distorcidas sobre a ciência, passando a uma compreensão da ciência como um campo interdisciplinar de conhecimentos, envolta em valores. Além disso, os futuros professores vivenciam um processo de ensino e aprendizagem por meio de situações problemáticas de forma dialógica, oportunizando uma formação pautada nos princípios da contextualização, humanização tomada de decisões e cultura de participação.

\section{REFERÊNCIAS}

AIKENHEAD, G. What is STS science teaching? In: J. Solomom; G. Aikenhead (org.); STS education: international perspectives on reform. New York: Teachers College Press, p.47-59, 1994

AULER, D. Interações entre ciência-tecnologia-sociedade no contexto da formação de professores de ciências, 2002. Tese (Doutorado em Educação) - Universidade Federal de Santa Catarina: Florianópolis, 2002.

AULER, D. Enfoque Ciência-Tecnologia-Sociedade: pressupostos para o contexto brasileiro. Ciência \& Ensino, Piracicaba, v. 1, n. especial, p. 1- 20, 2008.

AULER, D. Novos caminhos para a educação CTS: ampliando a participação. In: W. L. P. Santos; D. Auler (org.); CTS e educação científica: Desafios, tendências e resultados de pesquisa. Brasília: Editora Universidade de Brasília, p.73-99, 2011.

AUlER, D.; DELIZOICOV, D. Alfabetização científico-tecnológica para quê? Ensaio Pesquisa em Educação em Ciências, Belo Horizonte, v. 3, n. 2, p. 122-134, 2001.

BACHELARD, G. A formação do espírito científico: contribuição para uma psicanálise do conhecimento. Rio de Janeiro: Contraponto, 1996.

BRIZOLLA, F.; SILVA, L. M.; FAGUNDES, M. C. V. Ousadia emancipatória no ensino superior: relato de uma experiência didática no Campus Litoral da Universidade Federal do Paraná (UFPR). Revista Brasileira de Estudos Pedagógicos, Brasília, v. 91, n. 229, p. 584 -603, 2010. 
CARVALHO, A. M. P. DE; GIL-PÉREZ, D. Formação de professores de ciências: tendências e inovações. São Paulo: Cortez, 2011.

DAGNINO, R. O que é o PLACTS (Pensamento Latino-americano em Ciência, Tecnologia e Sociedade)? Ângulo, Lorena, v. 140, p. 47-62, 2015.

DAGNINO, R.; THOMAS, H.; DAVYT, A. El pensamiento en ciencia, tecnología y sociedad en Latinoamérica: una interpretación política de su trayectoria. Redes, Buenos Aires, v. 3, n. 7, p. 13-51, 1996.

FREIRE, P. Pedagogia da autonomia: Saberes necessários à prática educativa. $45^{\circ}$ ed. Rio de Janeiro: Editora Paz e Terra, 2013.

FREIRE, P. Pedagogia do Oprimido. 60ª ed. Rio de Janeiro: Paz e Terra, 2016.

GEREMIAS, B. M.; CASSIANI, S. A tecnologia como problema na educação CTS: análises de uma oficina de leitura na formação de professores de ciências. Revista Inter Ação, v. 41, n. 3, p. 743 - 762, 2016.

GIL-PÉREZ, D.; MONTORO, I. F.; ALÍS, J. C.; CACHAPUZ, A.; PRAIA, J. Para uma imagem não deformada do trabalho científico. Ciência \& Educação, Bauru, v. 7, n. 2, p. 125-153, 2001.

JOUCOSKI, E. Desenvolvimento profissional e inovação curricular na licenciatura em ciências da UFPR Litoral, 2015. Tese (Doutorado em Interunidades em Ensino de Ciências) Universidade de São Paulo: São Paulo, 2015.

LÜDKE, M.; ANDRÉ, M. E. D. A. Pesquisa em educação: abordagens qualitativas. Editora Pedagógica e Universitária, 1986.

MIRANDA, A. L. Da natureza da tecnologia: uma análise filosófica sobre as dimensões ontológica, epistemológica e axiológica da tecnologia moderna. 2002. Dissertação (Mestrado em Tecnologia), Centro Federal de Educação Tecnológica do Paraná: Curitiba, 2002.

MORAES, R.; GALIAZZI, M. C. Análise Textual Discursiva: processo reconstrutivo de múltiplas faces. Ciência \& Educação, Bauru, v. 12, n. 1, p. 117-128, 2006.

MORAES, R.; GALIAZZI, M. DO C. Análise textual discursiva. 2ª ed. Ijuí: Editora Unijuí, 2011.

RIBEIRO, T. V.; SANTOS, A. T.; GENOVESE, L. G. R. A história dominante do movimento CTS e o seu papel no subcampo brasileiro de pesquisa em ensino de ciências CTS. Revista Brasileira de Pesquisa em Educação em Ciências, Belo Horizonte, v. 17, n. 1, p. 13-43, 2017.

SANTOS, W. L. P. Contextualização no ensino de ciências por meio de temas CTS em uma perspectiva crítica. Ciência \& Ensino, Piracicaba, v. 1, n. Especial, p. 1-20, 2008.

SANTOS, W. L. P.; AULER, D. (ORGS.). CTS e educação científica: desafios, tendências e resultados de pesquisa. Brasília: Editora Universidade de Brasília, 2011.

SANTOS, W. L. P.; MORTIMER, E. F. Uma análise de pressupostos teóricos da abordagem CTS (Ciência-Tecnologia-Sociedade) no contexto da educação brasileira. Ensaio Pesquisa em educação em ciências, Belo Horizonte, v. 2, n. 2, p.1-23, 2002.

SILVA, L. M.; BRIZOLLA, F.; SILVA, L. E. DA. Projeto pedagógico do curso de licenciatura em Ciências da UFPR Litoral: desafios e possibilidades para uma formação emancipatória. Revista Brasileira de Estudos Pedagógicos, Brasília, v. 94, n. 237, p. 524-541, 2013. 
SILVA, V.; NICOLODI, S. C. F. Docência compartilhada como precursora de novas ações no espaço educacional. In: CONGRESSO IBERO - AMERICANO DE HUMANIDADES, CIÊNCIAS E EDUCAÇÃO: POLÍTICAS DE FORMAÇÃO NOS PAÍSES IBERO - AMERICANOS, 2, 2016, Criciúma. Anais[...] Criciúma: 30 nov. 2016.

SOLBES, J.; VILCHES, A. El modelo constructivista y las relaciones ciencia/técnica/sociedad. Enseñanza de las ciencias: revista de investigación y experiencias didácticas. Barcelona, v. 10, n. 2, p. 181-186, 1992.

UFPR. Projeto Político Pedagógico. Universidade Federal do Paraná, 2008.

UFPR. Projeto Pedagógico do Curso de Licenciatura em Ciências. Universidade Federal do Paraná, 2014.

VACCAREZZA, L. S. Ciencia, tecnología y sociedad: el estado de la cuestión en América Latina. Revista Iberoamericana de educación, Madrid, n. 18, p. 13-40, 1998.

VENTURA, M. M. O estudo de caso como modalidade de pesquisa. Revista da Sociedade de Cardiologia do Estado do Rio de Janeiro, Rio de Janeiro, n. 5., v. 20, p. 383-386, 2007.

Submetido em 31/07/2019

Aprovado em 19/11/2019

Contato:

Leonir Lorenzetti

Departamento de Química da UFPR

Av. Cel. Francisco H. dos Santos, n. 100 - Jardim das Américas

CEP 81.531-980, Curitiba, PR - Brasil 